\title{
EL 98 EN LA HABANA: SOCIEDAD Y VIDA COTIDIANA
}

\author{
POR \\ MARÍA DEL CARMEN BARCIA ZEQUEIRA \\ Facultad de Filosofía e Historia, Universidad de la Habana
}

\begin{abstract}
En este artículo se aborda la situación de La Habana a finales de los años noventa y específicamente la vida cotidiana antes y durante el bloqueo establecido por la flota de los Estados Unidos. Se hace hincapié en la vida de los hombres y mujeres anónimos que fueron los principales actores de aquella compleja etapa y en este contexto se destacan los elementos clasistas, étnicos y de género.
\end{abstract}

El año 1898 fue una fecha límite para Cuba, de igual forma que debió serlo para España y para los Estados Unidos. Y no sólo porque se rompiese la continuidad de un proceso que de una forma $u$ otra debió tener alternativas similares, sino porque la sociedad, al menos momentaneamente, se vió estremecida y conmocionada, salió de sus carriles y se enfrentó a situaciones que los historiadores, por lo general, no recojen ya que, en su escala de valores, no poseen una trascendencia significativa. Sin embargo esas circunstancias fueron, en su momento, dilemas existenciales y paradójicos para los individuos que los vivieron, sufrieron y padecieron. Esos hombres y mujeres anómimos fueron, incuestionablemente, los principales actores de aquella compleja etapa cuyo marco tratamos de reproducir en estas páginas.

\section{LA CAPITAL A FINALES DE LOS NOVENTA}

Si superficialmente la ciudad podía aparentar que su vida había cambiado poco, cuando se profundizaba en lo que estaba ocurriendo 
se evidenciaban los síntomas de una crisis profunda. El valor de las propiedades urbanas - que representaban la mayor riqueza imponible de la Capital-, era la mitad del que habían tenido en los años ochenta. El del Palacio Aldama, por ejemplo, había descendido de 250.000 a 120.000 pesos $^{1}$.

El año 1896 fue crítico para la capital de la Isla, la Invasión había traído los combates a sus puertas. Si a fines de año 95 habían emigrado muchas familias en previsión del extremismo de los integristas que hablaban de la necesidad de "echar la llave", a mediados del 96 comenzaban a salir los propios peninsulares con sus familias y sus capitales ${ }^{2}$.

La prensa destacaba que las familias que emigraban eran pudientes y que con ellas se iba el dinero; que la mayor parte iban para La Florida, que sacaría provecho de esta inmigración como lo había hecho con la del 68, que había levantado a Cayo Hueso; ahora le tocaba el turno a Tampa y a otras localidades de ese territorio ${ }^{3}$.

Los ricos no abrían sus salones con la prolijidad de años atrás; por lo general lo hacían sólo para los íntimos. Aún se mantenían los paseos familiares por las principales calles - Obispo y el Paseo del Prado sobre todo-, puntos de reunión de las familias distinguidas. Allí acudían las damas con sus guantes blancos de cabritilla, sus capotas con crisantemos -último grito de la moda-, y sus sombreros con plumas largas y negras 4 .

La vida cotiana resultaba difícil, los precios de los productos básicos se habían duplicado. Las capas populares se resentían de la situación, pero ésta también gravaba a familias que habían vivido holgadamente y ahora se veían precisadas a hipotecar sus propieda$\mathrm{des}^{5}$. La reconcentración de los campesinos había puesto en precario la producción agraria.

SIGLAS UTILIZADAS:

ANC: Archivo Nacional de Cuba (La Habana)

AHN: Archivo Histórico Nacional (Madrid)

1 "Información promovida en 1894", Revista de Agricultura, la Habana, año 15, no. 364/366. p. 29 a 32.

2 "Crónica", El Fígaro, la Habana, 24 de mayo de 1896, no. 19, p. 219.

3 "Crónica", El Fígaro, la Habana, 9 de febrero de 1896, no. 6, p. 66-67.

4 "Crónica", El Fígaro, la Habana, 12 de enero de 1896, no. 2, p. 23.

5 "nos vemos en la necesidad de tomar 6.000 pesos pagando sus intereses y me parece que por lo menos dos años, pues aunque tenemos rentas que cobrar(...) no contamos con ellas. Deseo saber si Ud. pudiera hacernos un favor (...) nosotros le daremos todas las segu- 
La prensa, en broma y en serio, se hacía eco de la situación. Tras el estallido de la guerra, en 1895 los elementos más reaccionarios de la sociedad, preocupados por el papel que ésta jugaba al evidenciar las situaciones sociales, políticas y económicas que se estaban produciendo - la miseria por una parte y la impasividad de aquellos que podían afrontarla por otra-, comenzaron a solicitar que se eliminase la libertad de imprenta que se había establecido en la Isla con la aplicación a ella de la Constitución de 1876. Justificaban la censura sobre la base de que ésta existía en otras naciones llamadas liberales y anti-republicanas ${ }^{6}$. De todas formas los periódicos progresistas continuaban evidenciando las situaciones que afrontaba la población:

\author{
"Es cosa muy peregrina \\ lo que entre nosostros pasa: \\ el billete sube y sube \\ pero los precios no bajan. \\ Cuando valía el centén ${ }^{7}$ \\ 15 pesos $^{8}$, se cobraba \\ en todas partes lo mismo \\ que hoy se cobra. \\ En esta Habana \\ toda alteración del oro \\ toda alteración de plata, \\ la fluctuación del billete, \\ todo se ordena y se fragua \\ para que explote el que vende \\ y se fastidie el que paga.
}

\begin{abstract}
ridades posibles en cafetales que tenemos en el campo y casas aquí en la Habana(...) aunque aquí pudiéramos hacer este negocio hay dos razones que nos sujetan: primero que nos pondrían un subido interés y segundo que se manifiestan más y los que no estamos acostumbrados a esto es para nosotros muy fuerte (...). Con Ud. es como un negocio de familia.

Joaquín Plana también le escribía a Marta Abreu el 7 de marzo de 1897. Le expresaba que debía más de un año y medio de la casa que habitaba por la que debía pagar 30 pesos al mes. Plana poseía 17 caballerías de tierra que en tiempos normales debía rentarle 3.000 pesos oro al año.

"Carta del 28 de marzo de 1897 a Marta Abreu, firmada por Teresa" y "Carta del 3 de marzo de 1897 a Marta Abreu, firmada por Joaquín Plana", Sala Cubana, Biblioteca Nacional "José Marti”, La Habana. Colección Manuscritos Abreu, 234. Vol 2.

6 El Comercio, uno de los periódicos más reaccionarios de la Habana en esos momentos, planteaba que "aunque somos una partícula de ese poder, sin embargo pedimos restricciones", ejemplar del 13 de septiembre de 1897, p. 1, c. 1 a 5.

7 El centén era una moneda de oro que equivalía a 5,30 pesos oro.

8 Se refiere a pesos billete y no oro.
\end{abstract}




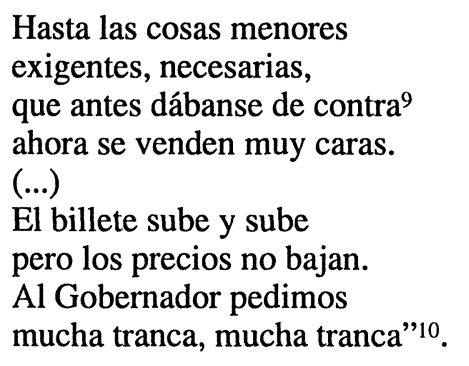

Los alimentos más asequibles a las capas pobres habían sido siempre las viandas ${ }^{11}$ pero ahora ocurría que:

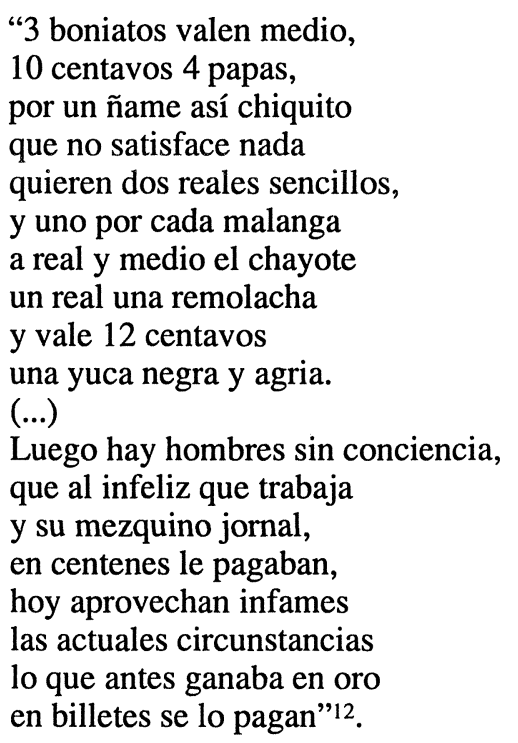

La situación con los precios de la carne llegó a ser escandalosa. En tiempos normales la capital consumía 300 reses diarias de 16 arrobas, 100 cerdos y 100 carneros. Se hacían gestiones para com-

\footnotetext{
9 Era común que los establecimientos diesen "de contra" es decir, gratuitamente a sus clientes, pequeñas cantidades de productos como azúcar o sal, por ejemplo.

10 "Los abusos del billete", La Lucha, la Habana, 6 julio de 1897, p. 2, c. 3.

11 Nombre que se da en Cuba a diferentes tubérculos comestibles. También se denomina de esta forma una variedad de plátano que es necesario cocinar.

12 Olallo DíAz GonZÁlez, La cuestión del pan. Imp. y Librería de M. Ricoy, La Habana, 1899.
}

R. I., $1998, \mathrm{n}^{\circ} 212$ 
prar la carne en Sancti Spíritus, pero el transporte, la mortalidad, la merma del peso durante el viaje, etc. la encarecían ${ }^{13}$, por estas razones se insistía en la necesidad de importarla. Se comentaba que los los propios encomenderos obstaculizaban la libre entrada del ganado en los corrales de Luyanó y en el matadero de la capital. Éstos formaban un trust que tenía el privelgeio de la matanza en el Rastro, razón por la cual controlaban la compra de ganado y también desde luego los precios de la carne ${ }^{14}$.

Un Bando de Weyler de agosto de 1897 prohibía vender las reses vivas a más de 1,50 pesos la arroba. Éstas serían adquiridas por los ayuntamientos para vender la libra a 0,20 la de toro novilla o vaca y a 0,25 la de ternera ${ }^{15}$. En la práctica la solución resultó más contraproducente que el problema, pues se obligaba a los labradores a entregar, con destino a la matanza, las vacas productoras de leche y los bueyes destinados al fomento de las áreas de cultivo ${ }^{16}$, de forma tal que se estaban afectando otras formas de consumo y de producción.

A pesar del precio establecido oficialmente la carne se anunciaba a o,30 plata la libra ${ }^{17}$. Esa situación contribuyó a que desde el mes de junio se incrementase la campaña de prensa:

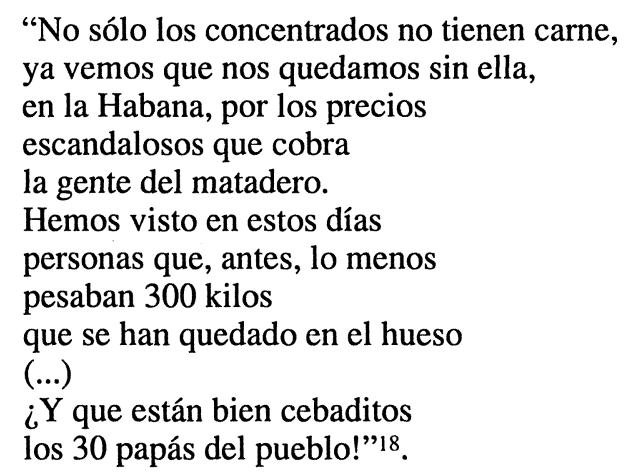

13 "La cuestión de la carne", La Lucha, 28 de junio de 1897, p. 2, c. 4.

14 "Córtese el nudo", El Comercio (edición de la tarde), la Habana, 10 enero de 1897, p. 2. c. 2 .

15 "Bando", La Lucha, la Habana, 16 de febrero de 1897, p. 2, c. 4

16 "El Bando del General y las zonas de cultivo", La Lucha, la Habana, 2 de agosto de 1897 , p. 2 , c. 1 y 2 .

17 “Anuncio del Mercado de Tacón, Casilla 15", La Lucha, 4 de enero de 1898, p. 4, c. 3 y 4 .

18 “¡Carne, carne!”, La Lucha, la Habana, 12 de julio de 1897, p. 2, c.4.

R.I., $1998, \mathrm{n}^{\circ} 212$ 
En el mes de septiembre de 1897 la prensa señalaba que la situación comenzaba a tener aspectos de calamidad pública ${ }^{19}$ :

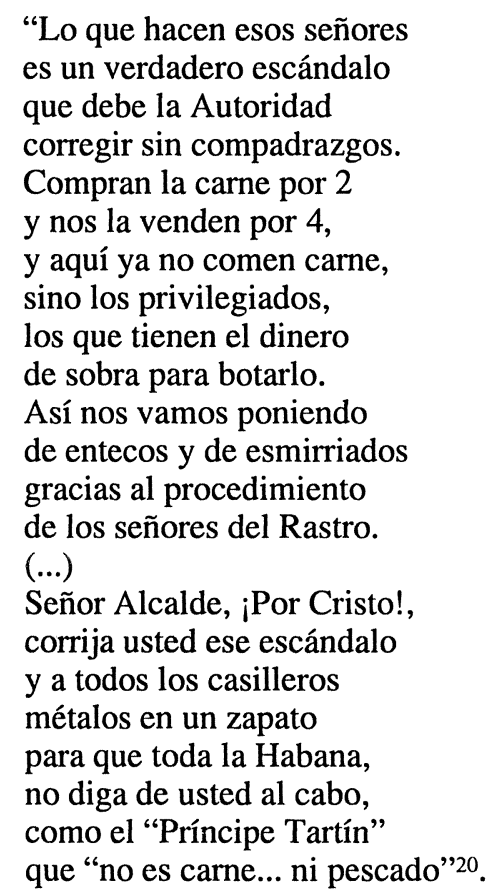

Aunque no levantaba tanto escándalo en la prensa, el problema del pan era similar pues el gremio que lo producía trataba de aprovechar la difícil situación para disminuir su tamaño y subirle el precio. De ello se hizo eco el juguete cómico La cuestión del pan que con un éxito enorme se presentó en el Teatro Alhambra el 11 de junio de $1897^{21}$.

La situación socioeconómica incidió en el incremento del marginalismo y de la prostitución. La vida de las mujeres era precaria, se desenvolvían en una esfera laboral limitada y ganaban, cuando más 35 pesos al mes. Una habitación costaba de 6 a 8 pesos mensuales y

\footnotetext{
19 "La carne", El Comercio, la Habana, 14 de septiembre de 1897, p. 1 c.5.

20 "Los casilleros", La Lucha, la Habana, 8 de septiembre de 1897, p. 2, c.3.

21 Véase [10]
}

R. I., $1998, \mathrm{n}^{\circ} 212$ 
debían gastar, aproximadamente 1 peso diario en alimentos ${ }^{22}$. Estos dos rubros rebasaban sus salarios. Paradójicamente algunas meretrices logran tener un nivel de vida superior ${ }^{23}$. Dos de ellas, muertas antes de finalizar el siglo, dejaron legados de 80.000 y 40.000 pesos oro respectivamente ${ }^{24}$.

La reconcentración incrementó apreciablemente las enfermedades, la marginalidad y también la prostitución, muchas mujeres vendían sus cuerpos para poder sobrevivir. En 1898 funcionaba la Quinta de Higiene San Antonio en la Calzada del Cerro, que era un hospital para prostitutas. Aún en un establecimiento de este tipo se marcaban las diferencias raciales y sociales, había salas para mujeres blancas y salas para mujeres negras, las enfermas graves podían disponer de cuartos de sólo cuatro camas y las meretrices, con mayores recursos económicos, pagaban cuartos independientes, extras en la alimentación y ropa de cama especial ${ }^{25}$.

En 1899 el $80 \%$ de las prostitutas eran cubanas y el $50 \%$ de éstas eran menores de 20 años. A finales del siglo las "guabinas" 26 abandonaron sus antiguas calles de Habana y Teniente Rey para extenderse por toda la ciudad ${ }^{27}$, especialmente por Amistad, Neptuno y San Miguel. También la prensa versificaba ese fenómeno:

"Y casi todas las casas

de pupilas: La Francesa,

la Asturiana de Aguacate,

la Curra de Compostela,

22 El 32,4\% de las prostitutas que existían en la Isla en 1889 trabajaban en la esfera de los servicios o tenían alguna profesión, la mayor parte eran criadas de manos, lavanderas y planchadoras, costureras y tabaqueras.

${ }^{23}$ La prensa reflejaba cotidianamente casos de prostitutas que eran robadas, en julio de 1897 se refiere a Gabriela Cañada a la cual su criado Santiago Pamplona le robó 80 centenes, 4 medias onzas, 70 pesos en billetes, 25 pesos plata, gafas de oro, un baso de planta y otros objetos, "Novedades", El Comercio, la Habana, 2 de julio de 1897, p. 3. c. 1.

24 Eugenio Molinet, Memoria informe de la Sección Médica de la Higiene Especial, la Habana, Imprenta de Francisco Xiqués. 1899, p. 155.

25 La clínica estaba ubicada en el número 440, junto al edificio de Obras Públicas. Las salas comunes tenían 16 camas. Había un comedor para "prostitutas distinguidas". Ibidem, p. 20.

26 Nombre que se daba a las prostitutas.

27 Una disposición del jefe de la Sección de Higiene, Dr. Eslava, eliminó los barrios especiales de prostitutas, extendiéndose esa situación a toda la Habana. El periódico $E l$ Pueblo, de la Habana, publicaba el 30 de julio de 1897, en la p. 3, c. 3, un artículo titulado "Carta Higiénica", que se refería a esa situación 


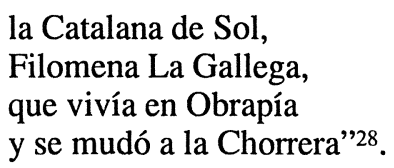

Otro fenómeno que conmocionaba la sociedad, paradójicamente, era el incremento de los turistas. Durante la etapa colonial muchos viajeros habían visitado la Isla, unos por curiosidad, otros por cuestiones de salud y muchos tratando de obtener información para sus negocios, pero a fines del siglo se apreciaba una diferencia en la calidad y procedencia de los visitantes, los norteamericanos tomaban posesión de nuestra ciudad y también de nuestro benévolo invierno.

Las mujeres recorrían en grupos las calles de Obispo y O'Reilly, se volvían locas por los abanicos que reproducían escenas toreras y compraban banderillas de lujo. Los hombres, cámara en mano, recorrían la Plaza de Armas, tomaban fotos del Castillo del Morro, visitaban la tumba de Colón y finalmente se iban a la Valla de Gallos. También organizaban excursiones al Vedado, Al Cerro y a Palatino $^{29}$. Los hoteles cambiaban su fisonomía y se adaptaban a la nueva situación: anunciaban tener baños con agua fría y caliente, elevadores y el conocimiento de varios idiomas para comunicarse con los huéspedes.

Las familias de la Habana y de Matanzas preferían veranear en Madruga. Allí había pequeños hoteles, el San Luis y La Quinta Pardiñas que se repletaban en los meses más cálidos ${ }^{30}$.

Otros aspectos de la vida moderna penetraban en la ciudad. El 2 de febrero de 1889 se ensayó la utilización de la luz eléctrica; ésta empezó a usarse en el Parque de Isabel la Católica y en el Parque Central el 3 de marzo de 1889. Se informó a la población que este servicio se daría a través de líneas soterradas, pero ésto no se hizo razón por la cual la prensa emplazaba a la empresa por el peligro a que se sometía a la población. ${ }^{31}$ En 1893 se inauguró el acueducto de Albear. Los fonógrafos y las cámaras fotográficas Kodak se anuncia-

28 Olallo Diaz GonZÁLEZ, [12], p. 14.

29 "Crónicas", El Fígaro, la Habana, 14 de febrero 1892, no. 5, p. 7.

30 "Crónicas", El Fígaro", la Habana, 3 de julio de 1892, no. 23, p. 7.

31 El Diario de la Marina se refería el 18 de enero de 1898 al trabajo del Dr. Claudio Delgado, presentado en la Real Academia de Ciencias Médicas, Físicas y Naturales de la Habana, titulado "Consideraciones sobre el alumbrado eléctrico de la Habana". 
ban en la prensa. Se generalizaban las cocinas de gas y el teléfono y la nueva fábrica de hielo y cerveza "La Tropical", propiedad de Cosme Blanco Herrera, hijo del conde de la Mortera, comenzaba a funcionar en agosto de 1897.32

El "choteo" cubano también hacía uso de la modernización:

"¡No dejará de ser eso cosa de los yanquis!. Esos demonios habrán de inventar una máquina para hacer niños artificiales que caminen lo mismo que los de carne y hueso (...)"33.

\section{AVATARES DE UNA CIUDAD BLOQUEADA.}

El 21 de abril de 1898 la marina norteamericana comenzó el bloqueo de las costas de Cuba. Ese mismo día el Gobierno español entregaba los pasaportes al embajador de los Estados Unidos y su personal. La situación, sobre todo en las ciudades y especialmente en la capital, se agudizó rápidamente.

Aparentemente la población permanecía tranquila y realizaba sus actividades normales, no obstante el número de jefes, oficiales o simples soldados del Ejército Español, Voluntarios y miembros del Cuerpo de Bomberos que circulaba por las calles de la capital se había incrementado apreciablemente. Los vecinos observaban el horizonte desde las azoteas tratando de ver los buques de guerra noreamericanos ${ }^{34}$. Una luz roja en el semáforo del Morro y tres cañonazos avisarían a la población el inicio de las maniobras de la flota enemiga ${ }^{35}$.

En los primeros días del mes de abril el Capitán General había ordenado realizar un padrón de vecinos para organizar rondas urbanas capaces de velar por el orden en los diferentes barrios en caso de guerra $^{36}$. Paralelamente, por las noches, se reunían en los parques y

\footnotetext{
32 La construcción de esta fábrica había comenzado en 1891, su reconstrucción, culminada en 1897, costó 60.000 pesos. La Lucha, la Habana, 2 agosto de 1897, p.3.

33 Olallo DiAZ GONZÁLEZ, [12], p. 15

34 "El tercer día", El Comercio, la Habana, edición de la tarde, 25 de abril de 1898, p. 1, c. $1-2$.

35 Idem.

36 "Rondas urbanas", El Comercio, la Habana, edición de la tarde, 9 de abril de 1898, p. 1 , c. $1-2$
} 
los paseos las compañías de Voluntarios con el objetivo de actualizar su preparación militar ${ }^{37}$.

El día 22, recién declarada la guerra, se estableció el Comité General de Defensa y se organizaron los Comités Patrióticos de Vigilancia Pública ${ }^{38}$. Los alcaldes de cada barrio debían convocar a los vecinos y elegir cuatro españoles para integrarlos; éstos, a su vez, escogían tres compatriotas por cada manzana o cuadra para formar los subcomités.

Los miembros de estas organizaciones llevaban un distintivo que permitía reconocerlos: dos banderitas españolas cruzadas, en el ojal izquierdo. En el Bando correspondiente se establecía que éstos tendrían el control de la población a nivel de cuadras a través de listas de vecinos en las cuales constaban las profesiones que éstos ejercían y si formaban parte del Cuerpo de Voluntarios. Para cambiar de residencia era necesario contar con una boleta de traslado. Se prohibía específicamente soltar palomas mensajeras o emplear luces, banderas u otros signos que pudieran parecer señales ${ }^{39}$.

El orden público quedaría en manos de los Voluntarios Urbanos dirigidos por el marqués de Argüelles, en tanto que por Orden General del Ejército de Operaciones se creaba una Brigada de Fuerzas Movilizadas que fue bautizada como "Cuba Española", al frente de la misma fue ubicado, como una manipulación más habida cuenta del número de oficiales peninsulares que había en la Isla, al ex-brigadier insurrecto Juan Masó Parra ${ }^{40}$, que recientemente había depuesto las armas ante las autoridades civiles.

En quince días la sociedad habanera se desquició. La capital pasó a ser, para las familias pudientes, una ciudad triste; para las modestas y menesterosas, una ciudad tétrica.

37 "Instrucción de Voluntarios", El Comercio, la Habana, edición de la tarde, 2 de abril de 1898 , p. 1 , c. $1-2$.

38 "Bando firmado por el Gral. Juan Arolas, Comandante General de las fuerzas de defensa de la plaza de la Habana", El Comercio, la Habana, edición de la tarde, 22 de abril de 1898 , p. 1 , c. 5 .

39 Idem.

40 "La Guerra Santa. La brigada Cuba Española", La Unión Constitucional, la Habana, 26 de abril de 1898. En: Archivo Nacional de Cuba, Fondo Asuntos Políticos, leg. 287, no. 4. El periódico La Lucha publicaba ese mismo día una foto de Masó Parra donde se decía que procedía de la Academia Militar de Guatemala, que era Comandante del Ejército Centro-Americano y Teniente General del Ejército de Venezuela. 
Las viejas quintas del Cerro habían perdido su función original, la de Leonor Herrera, con sus lagos y sus chalets era la Casa de Salud del Centro Asturiano, allí se instaló un hospital de sangre; la de Santovenia se había convertido en un asilo para ancianos desvalidos; la de Palatino en un sanatorio, y la de Güell era una venta pública de flores $^{41}$.

La cercanía de la guerra incrementó aceleradamente la emigración. El vapor Lafallette de la Compañía Francesa llevaba a los que huían temerosos de lo que podía ocurrir, hacia puertos neutrales como Veracruz o Cayo Hueso ${ }^{42}$, otros marchaban hacía Mérida.

La prensa integrista pedía que se tratase como "traidores" a los que abandonaban el país y que, para conocimiento general, se publicaran las listas de los que se marchaban. Entre ellos se encontraba una familia tan proespañola como la Ajuría. Pero también se iban muchos profesionales. Llama la atención la cantidad de licencias por enfermedad que presentaban, por ejemplo, los profesores. La Universidad de la Habana comenzó a cesantear, con carácter retroactivo, a los catedráticos que viajaban sin autorización. Este fenómeno se producía también con los maestros y otras personas con recursos para viajar ${ }^{43}$.

Las dificultades con los alimentos de primera necesidad se incrementaron. Sólo sobraba el azúcar pues los almacenes estaban abarrotados, media Habana se dedicó a fabricar melcochas, los vendedores voceaban: $¡$ A centavito la melcocha! ${ }^{44}$.

Los pobres tuvieron que sustituir el pan por los "bollitos de carita" - frituras de frijoles que hacían los chinos-, pues la libra de pan no se conseguía a menos de un peso y haciendo filas interminables $^{45}$. El General Arolas dispuso la distribución de 600 sacos de

41 El Fígaro, la Habana, 17 de julio de 1898 , no. 27, p. 340.

42 Isidoro CoRzo, El bloqueo de la Habana, la Habana, 1905, p.112-114.

43 Existen numerosos casos en el Fondo Instrucción Pública del ANC, legajos 695, 696, y 697.

44 Isidoro CoRzo, [42].

45 Fernández de Castro presentó su renuncia al cargo de Gobernador Civil en agosto del 98 pero Antonio Govín no la aceptó. Alegaba estar enfermo por el exceso de trabajo en las circunstancias excepcionales en que se encontraba la ciudad y señalaba "la absoluta carencia de recursos necesarios para atender debidamente la obra humanitaria (...) que en primer término procuraba realizar con el fin de salvar de la miseria, la perdición y la muerte a innumerables necesitados (...) procurando remediar las necesidades de muchos con donativos voluntarios que hacían los menos para suplir la falta de caridad de los más y 
harina, que poco significaban, desde luego, con el objetivo de acabar con "la rebeldía pasiva en que se hallan colocados los detallistas de la Habana 46 "

El Gobernador de la Habana, Rafael Fernández de Castro, organizaba festivales con la finalidad de recaudar dinero para dar de comer a los pobres ${ }^{47}$. El Gobierno Autonómico dió un crédito de 25.000 pesos para las cocinas gratuitas, éstas funcionaban en todos los barrios de la capital y sus alrededores ${ }^{48}$. La Cruz Roja Española por primera vez hacía algo por la población civil, visitaba la Lonja del Comercio y pedía a sus integrantes auxilio para las cocinas económicas ${ }^{49}$.

Los señores Bock y Cía, dueños de la Henry Clay, se dispusieron a dar de comer a los trabajadores de sus 4 fábricas de tabaco y 3 de cigarros, mientras durase la situación. Ésta era una forma de incentivarlos para concurrir a sus labores, aunque decían estar dispuestos a enviar la comida al domicilio de los que no quisiesen comer en las referidas fábricas ${ }^{50}$.

Ni las familias pudientes escapaban de la situación. Una revista de élites como era El Fígaro acostumbraba a sortear, entre sus sucriptoras un objeto, durante los años noventa este fue un lujoso abanico de nacar y encajes. En agosto de 1898 la situación aconsejaba algo más práctico, que sobre todo les permitiera mantener su clientela: la solución fue sortear un lote de víveres, pues en la escala de valores de ese momento aliviar el calor era menos importante que comer. El premio ofrecido consistía en: " 1 arroba de arroz, 1 arroba de tasajo, 1 arroba de bacalao, 1 arroba de frijoles negros, 1 arroba de friloles blancos, 1 arroba de garbanzos y una lata de manteca de 18 libras ${ }^{51}$ "

La prensa comentaba la situación de la ciudad:

\footnotetext{
"La actualidad se impone y hay que levantar acta de lo que pasa (...) cerrados los teatros, los paseos huérfanos de retretas, la miseria pa-
}

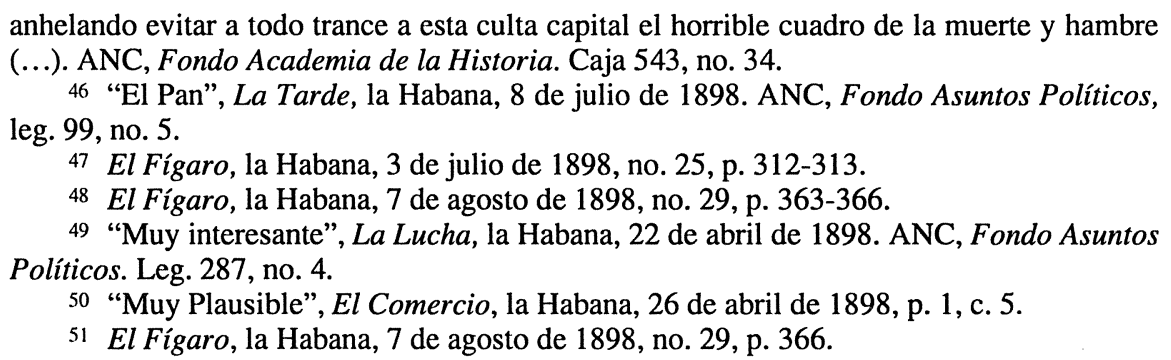

R. I., $1998, \mathrm{n}^{\circ} 212$ 
seándose por las calles (...) y además de establecimientos, se cierran círculos de recreo cuando se fundan cocinas para los pobres. El Restaurant Inglaterra ya no existe ni tampoco el Club Nacional (...) $)^{52 "}$.

Pero a partir del bloqueo los espectáculos disminuyeron paulatinamente. Todavía en el mes de mayo el teatro bufo daba algunas funciones, pues en Cuba podía perderse todo, todo menos el buen humor. Las obras que se exhibían aludían a la guerra y a la escasez de alimentos. En el Irijoa se presentaba "Pancho el guerrillero" y en el Alhambra "El bombardeo del mulo", haciendo referencia al animal que había muerto en el ataque por mar, al fuerte de San Severino. En el Albisu la Piquer cantaba:

\author{
Las mujeres de los yanquis \\ son muy feas y muy sosas \\ y en lugar de camisón \\ usan camiseta corta ${ }^{53}$.
}

Para entretener a la población temerosa y hambrienta, la charanga de la guarnición habanera, la de Puerto Rico y la Banda de Isabel la Católica tocaban en el Prado, en el Parque Central y en la Plaza de Armas. Los integristas comentaban "sólo falta que se reabran los teatros" -refiriéndose, desde luego, a los grandes espectáculos a que estaba acostumbrada la ciudad. Pero eso no era posible en una ciudad bloqueada y militarizada. Los espacios públicos no volverían a encontrar su lugar en la sociedad hasta unos meses después, en el año 1899 , en una sociedad intervenida por los yanquis.

La situación desesperada del Gobierno para adquirir víveres se manifestaba en la correspondencia oficial. Debido al bloqueo, los fondos para adquirir todo tipo de artículos tuvieron que ubicarse en Londres y gestionarse a través de individuos que viviesen fuera de la Isla. En el Crédito Lyonés se abrieron cuentas a nombre de los cónsules o encargados de negocios de España en Montreal, Nassau, Jamaica, Charleston, Port au Prince y México. Las cartas de Blanco Erenas al Ministro de Ultramar y a las personas que le servían de intermediarios en las compras reflejan la desesperación e impotencia que sentía

52 El Fígaro, la Habana, 10 de julio de 1898, no. 26, p. 329.

53 Olallo DíAZ GONZÁLEZ, [12], p. 72-73. 
en esos momentos. Tampoco había dinero para pagar al Ejército y en algunos lugares, Camagüey, por ejemplo, se producían movimientos sediciosos $^{54}$.

En medio de esa dramática situación se trataba de ocultar o de mediatizar lo que estaba ocurriendo en el país. Cuando la escuadra española fue derrotada en Santiago de Cuba, muchos vendedores de periódicos al reflejar en sus pregones lo ocurrido eran detenidos por las autoridades con el pretexto de que alteraban el orden ${ }^{55}$. El periódico La Tarde del 5 de julio, publicaba la siguiente advertencia: "queda terminantemente prohibido a los vendedores gritar "Última Hora".

En septiembre de 1898 fueron detenidos muchos ciudadanos por gritar ¡Viva Cuba Libre! ${ }^{56}$, la mayor parte eran jóvenes trabajadores entre 18 y 27 años ${ }^{57}$. Todavía en el mes de octubre, ya perdida la guerra, se requisaban periódicos independentistas como El Grito de Yara, La Estrella Solitaria, El Mambí, La Independencia, La República Cubana ${ }^{58}$ y se detenía a los vendedores, a los que portaran banderas cubanas o norteamericanas ${ }^{59} \mathrm{o}$ a los que tocaran o cantaran el himno de Bayamo ${ }^{60}$.

En el mes de diciembre la Habana se mostraba aún triste en su aspecto (...) los teatros cerrados, los simones o coches de alquiler guardados en sus establos, los trabajadores paralizados en sus faenas, todo revelaba silencio, desgracia, hambre y desnude $z^{61}$.

No obstante algunos cafés como el Tacón, el Central y el Inglaterra mantenían alumbrados sus salones a los que aún acudían los

\footnotetext{
${ }^{54} \mathrm{La}$ correspondencia que se cita puede ser consultada en el AHN, Fondo Ultramar, Gobierno, leg. 4963.

55 Muchos expedientes con esta información pueden ser encontrados en el ANC, Fondo Asuntos Políticos, legajo 99.

56 Idem.

57 Pintores, tabaqueros, sastres, mecánicos y dependientes de comercios.

58 Véase [47].

59 El 2 de noviembre de 1898 fue detenido en Pardo Tomás Johnson, súbdito norteamericano, de Atlanta, de 28 años de edad, casado y jornalero, vecino de San Juan de Dios. Fue arrestado en el Parque Central por llevar "más de 10 banderas tituladas cubanas y 11 americanas". ANC, Fondo Asuntos Políticos, legajo 99, no. 31.

60 El 11 de octubre de 1898 fueron detenidos Agustín Martínez Rodríguez, asturiano de 52 años, dueño del café La Reina, y Horacio Valdés Carrasco por tocar al piano el himno de Bayamo. ANC, Fondo Asuntos Politicos, legajo 99, no. 21.

61 Juan Canales Carazo. Cuba por dentro, 1898 - 1906, s/f, s/e, p. 12.
} 
oficiales españoles que no parecían percibir que su preponderancia en el país había finalizado ${ }^{62}$.

En el mes de diciembre, esperando la evacuación de las tropas, la ciudad estaba tácitamente dividida, en los portales del Paseo de Tacón, Prado y de el Payret, se concentraban los soldados del Ejército Español, envueltos en sus mantas, anémicos, temblando por efecto de las fiebres palúdicas ${ }^{63}$, en Galiano, Reina, Príncipe y Ancha del Norte, ondeaba la bandera cubana. El Parque de la India y los cuarteles de Dragones y Príncipe, aparecían vestidos de limpio, albergando a los militares norteamericanos ${ }^{64}$.

Por la calle cruzaban algunos cubanos cantando "guarachas" y canciones, otros se preparaban para embanderar las casas. Los festejos se inciarían por el barrio de Puentes Grandes ${ }^{65}$.

El 23 de diciembre las tropas españolas eran evacuadas de la Habana. Las campanas de las iglesias de Jesús María y San Nicolás comenzaron a repicar ${ }^{66}$. Las ambulancias, ocupadas por oficiales norteamericanos recorrían la ciudad, las brigadas de saneamiento, desinfectaban los edificios y votaban a la calle lo que consideraban inservible. Una nueva época se diseñaba, la intervención tocaba a las puertas.

The author discusses the situation in Havana in the 1890's, specifically the city's everyday life before after the blockade by the U.S. fleet. She emphasizes the living conditions of anonymous men and women, the main actors in that complex time and place divided by class and ethnicity as well as gender.

62 Idem.

63 Idem.

64 Ibidem, p. 22.

65 "Carta de Francisco Pérez al Sr. Orejudo", 17 de diciembre de 1898. ANC, Fondo Asuntos Políticos, leg. 99. No. 37.

66 ANC, Fondo Asuntos Políticos, leg. 99, no. 39. 